\title{
Clinical significance of NUCB2 mRNA expression in prostate cancer
}

\author{
Hongtuan Zhang ${ }^{1}$, Can $\mathrm{Qi}^{1}$, Liang $\mathrm{Li}^{2}$, Fei Luo ${ }^{1}$ and Yong Xu${ }^{1 *}$
}

\begin{abstract}
Background: Nucleobindin 2 (NUCB2) abnormal expression has been reported in gastric cancer and breast cancer. However, the role of NUCB2 in prostate cancer (PCa) remains unclear. The aim of the present study was to investigate the NUCB2 expression in PCa tissues and adjacent non-cancerous tissues and its potential relevance to clinicopathological variables and prognosis.

Methods: NUCB2 mRNA expression was determined by real-time quantitative real time reverse transcriptase polymerase chain reaction in 180 pairs of fresh frozen PCa tissues and corresponding non-cancerous tissues. KaplanMeier analysis and Cox proportional hazards regression models were used to investigate the correlation between NUCB2 expression and prognosis of PCa patients.

Results: Our results showed that the expression level of NUCB2 mRNA in PCa tissues was significantly higher than those in non-cancerous tissues. Our results indicated that the high expression of NUCB2 in PCa was associated with lymph node metastasis, preoperative PSA, Gleason score, and angiolymphatic invasion. Kaplan-Meier survival analysis showed that patients with high NUCB2 expression have shorter biochemical recurrence (BCR)-free survival time compared to patients with low NUCB2 expression. Multivariate analysis revealed that NUCB2 expression was an independent predictor of BCR-free survival.
\end{abstract}

Conclusions: NUCB2 might play a positive role in PCa development and could serve as an independent predictor of BCR-free survival.

\section{Background}

Prostate cancer $(\mathrm{PCa})$ is one of the most frequently diagnosed malignancies and a common cause of cancer mortality in men in the Western hemisphere [1], which has become a major public health challenge. In China, the incidence of $\mathrm{PCa}$ has been increasing continually in the most recent years. Although we have made considerable advances in diagnosis and adjuvant therapy of $\mathrm{PCa}$, the overall survival rate of PCa patients has not been improved markedly. The mechanism of its carcinogenesis, like other cancers, is still not fully understood. It is a clinically heterogeneous, multifocal disease. Carcinogenesis and mechanisms influencing progression and prognosis of $\mathrm{PCa}$ are a multi-step process, involving both genetic insults to epithelial cells and changes in epithelial-stromal interactions [2]. Conventional prognostic factors such as

\footnotetext{
* Correspondence: xymnwk@163.com

${ }^{1}$ National Key Clinical Specialty of Urology, Tianjin Key Institute of Urology, Second Affiliated Hospital of Tianjin Medical University, Tianjin, China Full list of author information is available at the end of the article
}

Gleason score, preoperative PSA levels or ratio of involved biopsies only insufficiently predict patient outcome for currently available therapies. They are even more limited in identifying insignificant PCa. Therefore, there is an urgent need for better understanding of PCa pathogenesis which may lead to more effective treatment strategies [3-5].

Nucleobindin 2 (NUCB2) has a characteristic constitution of functional domains, such as a signal peptide, a Leu/lle rich region, two $\mathrm{Ca}^{2+}$ binding EF-hand domains separated by an acidic amino acid-rich region, and a leucine zipper [6,7], and has a wide variety of basic cellular functions [8-10]. NUCB2 is known to mainly express in key hypothalamic nuclei with proven roles in energy homeostasis [8]. Moreover, recent studies have indicated that NUCB2 is also expressed in various human peripheral tissues, including the stomach, pancreas, reproductive organs, and adipose tissues, with relevant metabolic functions, suggesting that NUCB2 signaling might participate in adaptative responses and in the control of

\section{Biomed Central}


body functions gated by the state of energy reserves [11]. NUCB2 has been studied in breast cancer and gastric cancer $[12,13]$. To the best of our knowledge, NUCB2 has not yet been studied in PCa. Little is known about the expression of NUCB2 in PCa, and data on its potential prognostic value in $\mathrm{PCa}$ are completely lacking. Therefore, we examined NUCB2 in PCa using quantitative real time reverse transcriptase polymerase chain reaction (qRT-PCR) to explore its clinical significance.

In this study, the mRNA expression of NUCB2 was measured in PCa tissues and adjacent non-cancerous tissues by qRT-PCR. We studied the correlation between the relative expression of NUCB2 and clinicopathological parameters to evaluate its clinical significance. Additionally, we assessed the influence of NUCB2 expression on the biochemical recurrence (BCR) of PCa patients.

\section{Materials and methods}

\section{Patient and tissue samples}

The study was approved by the research ethics committee of Tianjin medical university. Informed consent was obtained from all of the patients. All specimens were handled and made anonymous according to the ethical and legal standards. PCa samples $(\mathrm{n}=180)$ and adjacent noncancerous tissues $(n=180)$ were collected from patients with $\mathrm{PCa}$ who underwent radical prostatectomy and were diagnosed at the second hospital of Tianjin medical university between 1999 and 2010 were retrieved for the study. None of the patients received androgen deprivation treatment, chemotherapy, or radiation therapy prior to radical prostatectomy. The tissue samples were snapfrozen in liquid nitrogen and stored at $-80^{\circ} \mathrm{C}$ until used. The histopathology of each specimen was reviewed on the HE-stained tissue section to confirm diagnosis and tumor content at least $70 \%$ of tumor cells in the tissue sample. The following biochemical and pathological parameters were recorded: biochemical relapse, preoperative serum prostate-specific antigen (PSA), Gleason score, pathological stage, lymph node status, angiolymphatic invasion, margin status, and seminal vesicle invasion. The time to biochemical relapse was defined as the period between surgical treatment and the measurement of two successive values of serum PSA level $\geq 0.2 \mathrm{ng} / \mathrm{ml}$.

\section{Isolation of RNA and qRT-PCR analysis}

qRT-PCR was performed to determine the expression of NUCB2 mRNA. Briefly, the total RNA was extracted from frozen tissue by homogenization with a power homogenizer in TRIzol Reagent (Applied Invitrogen, Carlsbad, CA, USA) according to the manufacturer's protocol (Life Technologies) and reverse-transcribed to generate cDNA (PrimeScript RT-PCR kit; Takara Bio). Human $\beta$-actin was amplified as an endogenous control. The levels of mRNA encoding were quantified by real- time PCR with the Applied Biosystems 7900HT Fast Real-Time PCR System using SYBR Premix Ex Taq (Applied Takara Bio). The sequences of the primers were as follows: human NUCB2 forward 5-AAAGAAGAGCTA CAACGTCA-3' and reverse 5'-GTGGCTCAAACTTC AATTC-3'; human $\beta$-actin forward 5'-TGACGTGGA CATCCGCAAAG-3' and reverse 5'-CTGGAAGGTG GACAGCGAGG-3. The PCR conditions included an initial denaturation step of $94^{\circ} \mathrm{C}$ for $2 \mathrm{~min}$, followed by 35 cycles of $94^{\circ} \mathrm{C}$ for $30 \mathrm{~s}, 60^{\circ} \mathrm{C}$ for $20 \mathrm{~s}, 72^{\circ} \mathrm{C}$ for $2 \mathrm{~min}$, and a final elongation step of $72^{\circ} \mathrm{C}$ for $10 \mathrm{~min}$. All qRTPCRs were performed in triplicate. The relative gene expression was calculated by the equation $2^{-\Delta \Delta C T}$.

\section{Statistical analysis}

qRT-PCR data were calculated with StepOne Software v2.1 (Applied Biosystems, Carlsbad, CA). Measurement data were analyzed by Student's t-test, while categorical data were analyzed by chi-square test. The postoperative survival rate was analyzed with Kaplan-Meier method, and the log-rank test was used to assess the significance of differences between survival curves. The statistical analyses were performed using SPSS 16.0 software (SPSS, Chicago, IL, USA). All differences were considered statistically significant if the $P$ value was $<0.05$.

\section{Results}

NUCB2 mRNA expression in PCa and adjacent noncancerous tissues

The expression of NUCB2 mRNA was detected and analyzed in 180 pairs of $\mathrm{PCa}$ and adjacent non-cancerous tissues. The qRT-PCR results showed that the NUCB2 mRNA level was significantly higher in PCa tissues compared to that in adjacent non-cancerous tissues.

\section{Relationship between NUCB2 mRNA expression and clinicopathological variables}

The mRNA expression of the NUCB2 was categorized as low or high in relation to the median value. We investigated the relationship between NUCB2 mRNA expression status and commonly used clinicopathological parameters in PCa. The association of NUCB2 mRNA expression with the clinicopathological parameters of PCa patients is shown in Table 1. The upregulation of NUCB2 mRNA in PCa tissues was correlated with the higher Gleason score $(\mathrm{P}<0.001)$, the higher level of preoperative PSA $(\mathrm{P}=0.004)$, the positive lymph node metastasis $(\mathrm{P}=0.022)$, and the positive angiolymphatic invasion $(P=0.004)$. However, the NUCB2 mRNA expression was not related to age, seminal vesicle invasion, pathological stage, and surgical margin status. 
Table 1 Main characteristics of studies included in this meta-analysis

\begin{tabular}{|c|c|c|c|c|c|}
\hline \multirow[b]{2}{*}{ Variable } & \multirow[b]{2}{*}{ Group } & \multicolumn{3}{|c|}{ NUCB2 mRNA expression } & \multirow[b]{2}{*}{$P$ value } \\
\hline & & High & Low & Total & \\
\hline \multirow[t]{3}{*}{ Age } & & & & & 0.100 \\
\hline & $<70$ & $43(44.3 \%)$ & $54(55.7 \%)$ & 97 & \\
\hline & $\geq 70$ & $47(56.6 \%)$ & $36(43.4 \%)$ & 83 & \\
\hline \multirow[t]{3}{*}{ Lymph node metastasis } & & & & & 0.022 \\
\hline & Negtive & $77(47.2 \%)$ & $86(52.8 \%)$ & 163 & \\
\hline & Positive & $13(76.5 \%)$ & $4(23.5 \%)$ & 17 & \\
\hline \multirow[t]{3}{*}{ Surgical margin status } & & & & & 0.578 \\
\hline & Negtive & $82(49.4 \%)$ & $84(50.6 \%)$ & 166 & \\
\hline & Positive & $8(57.1 \%)$ & $6(42.9 \%)$ & 14 & \\
\hline \multirow[t]{3}{*}{ Seminal vesicle invasion } & & & & & 0.202 \\
\hline & Negtive & $67(46.2 \%)$ & $78(53.8 \%)$ & 145 & \\
\hline & Positive & $23(65.7 \%)$ & $12(34.3 \%)$ & 35 & \\
\hline \multirow[t]{3}{*}{ Clinical stage } & & & & & 0.880 \\
\hline & $\mathrm{T} 1$ & $52(50.5 \%)$ & $51(49.5 \%)$ & 103 & \\
\hline & $\mathrm{T} 2 / \mathrm{T} 3$ & $38(49.4 \%)$ & $39(50.6 \%)$ & 77 & \\
\hline \multirow[t]{4}{*}{ Preoperative PSA } & & & & & 0.004 \\
\hline & $<4$ & $1(20 \%)$ & $4(80 \%)$ & 5 & \\
\hline & $4-10$ & $23(35.9)$ & $41(64.1 \%)$ & 64 & \\
\hline & $>10$ & $66(59.5 \%)$ & $45(40.5 \%)$ & 111 & \\
\hline \multicolumn{6}{|l|}{ Gleason score } \\
\hline & $<7$ & $35(35.4 \%)$ & $64(64.6 \%)$ & 99 & $<0.001$ \\
\hline & 7 & 19 (55.9\%) & $15(44.1 \%)$ & 34 & \\
\hline & $>7$ & $36(76.6 \%)$ & $11(23.4 \%)$ & 47 & \\
\hline \multirow[t]{3}{*}{ Angiolymphatic invasion } & & & & & 0.004 \\
\hline & Negtive & $66(44.9 \%)$ & $81(55.1 \%)$ & 147 & \\
\hline & Positive & $24(72.7 \%)$ & $9(27.3 \%)$ & 33 & \\
\hline
\end{tabular}

NUCB2 mRNA expression to predict clinical outcome after radical prostatectomy

To examine if NUCB2 expression level is a significant predictor of BCR-free time after radical prostatectomy, Kaplan-Meier curves were plotted between high or low NUCB2 mRNA and BCR-free time. The low NUCB2 mRNA expression had significantly longer BCR-free time after radical prostatectomy compared to patients with high NUCB2 mRNA expression $(\mathrm{P}<0.001$; Figure 1$)$. In univariate analysis with Cox proportional hazards model, Gleason score, NUCB2 expression, and seminal vesicle invasion were confirmed as significant prognostic factors for BCR-free survival times whereas age, angiolymphatic invasion, surgical margin status, pathological stage and preoperative PSA were not significant factors (Table 2). Furthermore, the multivariate analyses showed that the upregulation of NUCB2 mRNA, higher Gleason score, and Seminal vesicle invasion were independent predictors of shorter BCR-free survival (Table 2).

\section{Discussion}

The identification of prognostic and predictive markers is clinically important, because $\mathrm{PCa}$ is heterogenous in respect to genetics, and variable in biological and clinical features. $\mathrm{PCa}$ is a heterogeneous-multifocal disease with a clinical outcome difficult to predict $[14,15]$. It is of great significance to identify novel diagnostic and prognostic markers to understand this multifaceted disease process [16-19]. An accurate and early diagnosis is essential for efficient management of PCa [20]. Therefore, to complement improvements in the clinical management, substantial progress in the diagnostic pathway of PCa is urgently needed [21-23].

To our knowledge, this is the first report to investigate the association between NUCB2 and PCa. The main findings of the present study are as following three points. First, qRT-PCR analysis found that NUCB2 mRNA expression was upregulated in PCa tissues compared with those in adjacent non-cancerous tissues. 


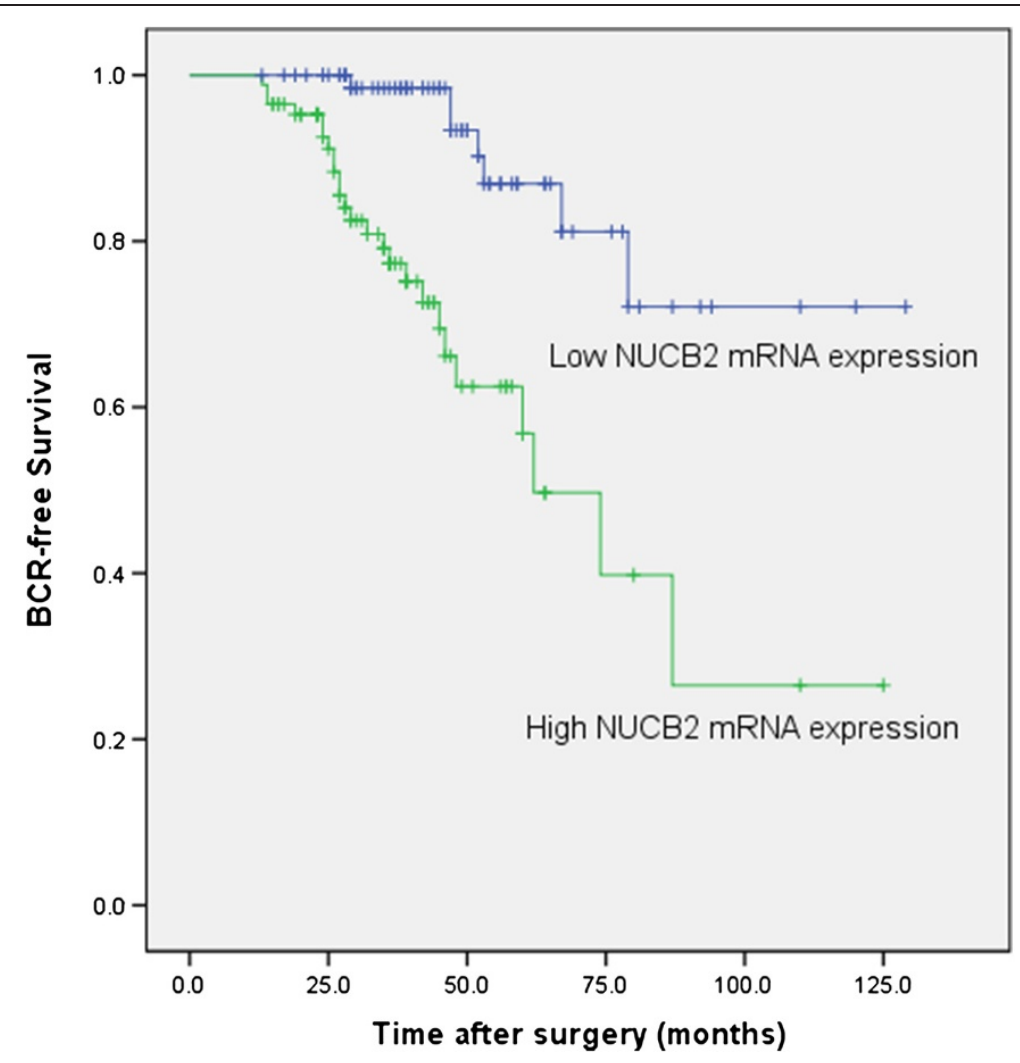

Figure 1 Associations between NUCB2 expression and BCR-free time after radical prostatectomy in PCa patients. Patients with high NUCB2 expression showed significantly shorter BCR-free survival than those with low NUCB2 expression ( $<<0.001$, log-rank test).

Second, this is the first report to describe the significance of NUCB2 to preoperative PSA, gleason score, angiolymphatic invasion, lymph node metastasis of $\mathrm{PCa}$ patients. Third, we proved that NUCB2 expression was significantly associated with BCR-free survival of $\mathrm{PCa}$ patients. In support of this, Kaplan-Meier analysis of BCR-free survival showed that patients whose tumors had high NUCB2 expression tend to have a significantly shorter BCR-free survival, indicating that high NUCB2 level is a marker of poor prognosis for BCR-free survival of PCa patients. The multivariate analyses showed that the upregulation of NUCB2 was an independent predictor of shorter BCR-free survival in $\mathrm{PCa}$ patients. These results suggest that NUCB2 may play important roles in the pathogenesis and aggressiveness of $\mathrm{PCa}$, and NUCB2 upregulation especially be associated with the unfavorable prognosis in $\mathrm{PCa}$. The precise molecular mechanisms behind the altered expression of NUCB2 in

Table 2 Prognostic value of NUCB2 mRNA expression for the biochemical recurrence-free survival in univariate and multivariate analyses by Cox regression

\begin{tabular}{|c|c|c|c|c|c|c|}
\hline \multirow[b]{2}{*}{ Covariant } & \multicolumn{3}{|c|}{ Univariate analysis } & \multicolumn{3}{|c|}{ Multivariate analysis } \\
\hline & $\operatorname{Exp}(B)$ & $95 \% \mathrm{Cl}$ & $P$ value & $\operatorname{Exp}(B)$ & $95 \% \mathrm{Cl}$ & $P$ value \\
\hline NUCB2 expression & 3.120 & $1.692-5.754$ & $<0.001$ & 2.900 & $1.569-5.360$ & 0.001 \\
\hline Gleason score & 1.703 & $1.280-2.265$ & $<0.001$ & 1.663 & $1.250-2.211$ & $<0.001$ \\
\hline Preoperative PSA & 1.241 & $0.705-2.188$ & 0.454 & & & \\
\hline Age & 1.068 & $0.804-1.419$ & 0.650 & & & \\
\hline Angiolymphatic invasion & 1.084 & $0.814-1.443$ & 0.580 & & & \\
\hline Surgical margin status & 1.017 & $0.709-1.459$ & 0.925 & & & \\
\hline PCa Stage & 1.090 & $0.921-1.291$ & 0.316 & & & \\
\hline Lymph node metastasis & 1.140 & $0.850-1.528$ & 0.381 & & & \\
\hline Seminal vesicle invasion & 1.505 & $1.132-2.003$ & 0.005 & 1.410 & $1.060-1.876$ & 0.018 \\
\hline
\end{tabular}


PCa are unclear. Additional studies to investigate the real molecular mechanisms of altered expression of NUCB2 in the development or progression of $\mathrm{PCa}$ are essential.

Currently, the advantages of serum PSA as a general PCa biomarker are viewed with intense skepticism [24]. The present study shows that NUCB2 classical mRNA transcript expression levels, assayed by a specific qPCR in prostate tissue samples, can improve $\mathrm{PCa}$ management by making available important and independent differential prognostic information. A variety of algorithms and nomograms that calculate the probabilities of BCR-free survival after treatment have been used in order to direct clinicians into the most suitable treatment options for PCa patients [25]; nonetheless patients still present unforeseen disease course patterns. Cox proportional hazards model showed that high NUCB2 expression was an independent prognostic predictor for PCa patients. Therefore, NUCB2 could constitute a molecular prognostic marker for $\mathrm{PCa}$ patients, identifying who are more likely to have higher risk of BCR and need receive a more aggressive treatment. Our findings could help establish a more personalized medicine-focused approach, where not only PSA, but also other novel and promising biomolecules will contribute to the multifactorial repertoire of individualized PCa care.

\section{Conclusions}

In conclusion, our data offer the convincing evidence for the first time that that NUCB2 mRNA were upregulated in PCa tissues. Our study revealed that NUCB2 is an independent prognostic factor for BCR-free survival in patients with PCa. High expression of NUCB2 in PCa is strongly correlated with preoperative PSA, gleason score, angiolymphatic invasion, and lymph node metastasis. These findings suggest that NUCB2 is a cancer-related gene associated with the aggressive progression and a BCR-free survival predictor of $\mathrm{PCa}$ patients. However, these results, which are based on a Chinese cohort, should be further confirmed in other populations of patients with PCa. Our findings suggest that NUCB2 might be used as a new biomarker and a potential therapeutic target for PCa.

\section{Consent}

Written informed consent was obtained from the patient for publication of this report and any accompanying images.

\section{Abbreviations}

NUCB2: Nucleobindin 2; PCa: Prostate cancer; BCR: Biochemical recurrence; OR: Odds ratio; Cl: Confidence interval; qRT-PCR: Quantitative real time reverse transcriptase polymerase chain reaction.

\section{Competing interests}

The authors declare that they have no competing interests.

\section{Authors' contributions}

$\mathrm{ZH}, \mathrm{QC}$ and $\mathrm{XY}$ conceived and designed the study, performed the experiments and wrote the paper. $\mathrm{ZH}$ and $\mathrm{XY}$ contributed to the writing and to the critical reading of the paper. ZH, QC, LL performed patient collection and clinical data interpretation. $\mathrm{ZH}$ and $\mathrm{LL}$ participated performed the statistical analysis. All authors read and approved the final manuscript.

\section{Acknowledgements}

This study was supported by the National Natural Science Foundation of China (NO: 81172451), Tianjin Major Anti-Cancer Project (12ZCDZSY17201), and Science Foundation of Tianjin medical university (NO: 2009GSI18).

\section{Author details}

'National Key Clinical Specialty of Urology, Tianjin Key Institute of Urology, Second Affiliated Hospital of Tianjin Medical University, Tianjin, China. ${ }^{2}$ Laboratory of Population and Quantitative Genetics, School of Life Sciences, Tianjin Medical University, Tianjin, China.

Received: 25 July 2013 Accepted: 16 August 2013

Published: 16 August 2013

\section{References}

1. Siegel R, Naishadham D, Jemal A: Cancer statistics, 2013. CA Cancer J Clin 2013, 63:11-30.

2. Klotz L: Hormone therapy for patients with prostate carcinoma. Cancer 2000, 88(12 Suppl):3009-3014.

3. Andren O, Fall K, Franzen L, Andersson SO, Johansson JE, Rubin MA: How well does the Gleason score predict prostate cancer death? A 20-year followup of a population based cohort in Sweden. J Urol 2006, 175 (4):1337-1340.

4. Vaarala MH, Väisänen MR, Ristimäki A: CIP2A expression is increased in prostate cancer. J Exp Clin Cancer Res 2010, 29:136.

5. Ben Jemaa A, Bouraoui Y, Sallami S, Banasr A, Ben Rais N, Ouertani L, Nouira Y, Horchani A, Oueslati R: Co-expression and impact of prostate specific membrane antigen and prostate specific antigen in prostatic pathologies. J Exp Clin Cancer Res 2010, 29:171.

6. Miura K, Titani K, Kurosawa Y, Kanai Y: Molecular cloning of nucleobindin, a novel DNA-binding protein that contains both a signal peptide and a leucine zipper structure. Biochem Biophys Res Commun 1992, 187(1):375-380.

7. Barnikol-Watanabe S, Gross NA, Götz H, Henkel T, Karabinos A, Kratzin H, Barnikol HU, Hilschmann N: Human protein NEFA, a novel DNA binding/ EF-hand/leucine zipper protein. Molecular cloning and sequence analysis of the CDNA, isolation and characterization of the protein. Biol Chem Hoppe Seyler 1994, 375(8):497-512.

8. Oh-I S, Shimizu H, Satoh T, Okada S, Adachi S, Inoue K, Equchi H, Yamamoto M, Imaki T, Hashimoto K, Tsuchiya T, Monden T, Horiguchi K, Yamada M, Mori M: Identification of nesfatin-1 as a satiety molecule in the hypothalamus. Nature 2006, 443(7112):709-712.

9. Taniguchi N, Taniura H, Niinobe M, Takayama C, Tominaga-Yoshino K, Ogura A, Yoshikawa K: The postmitotic growth suppressor necdin interacts with a calcium-binding protein (NEFA) in neuronal cytoplasm. J Biol Chem 2000, 275(41):31674-31681.

10. Islam A, Adamik B, Hawari FI, Ma G, Rouhani FN, Zhang J, Levine SJ: Extracellular TNFR1 release requires the calcium-dependent formation of a nucleobindin 2-ARTS-1 complex. J Biol Chem 2006, 281(10):6860-6873.

11. García-Galiano D, Navarro VM, Gaytan F, Tena-Sempere M: Expanding roles of NUCB2/nesfatin-1 in neuroendocrine regulation. J Mol Endocrinol 2010, 45(5):281-290.

12. Kalnina Z, Silina K, Bruvere R, Gabruseva N, Stengrevics A, Barnikol-Watanabe $S$, Leja M, Line A: Molecular characterisation and expression analysis of SEREX-defined antigen NUCB2 in gastric epithelium, gastritis and gastric cancer. Eur J Histochem 2009, 53(1):7-18.

13. Suzuki S, Takagi K, Miki Y, Onodera Y, Akahira J, Ebata A, Ishida T, Watanabe $M$, Sasano H, Suzuki T: Nucleobindin 2 in human breast carcinoma as a potent prognostic factor. Cancer Sci 2012, 103(1):136-143.

14. Filella X, Alcover J, Molina R: Active surveillance in prostate cancer: the need to standardize. Tumor Biol 2011, 32(5):839-843.

15. Carlsson J: Potential for clinical radionuclide-based imaging and therapy of common cancers expressing EGFR-family receptors. Tumor Biol 2012, 33(3):653-659. 
16. Kazma R, Mefford JA, Cheng I, Plummer SJ, Levin AM, Rybicki BA, Casey G, Witte JS: Association of the innate immunity and inflammation pathway with advanced prostate cancer risk. PLoS One 2012, 7(12):e51680.

17. Tassidis $H$, Brokken $\sqcup$, Jirström K, Bjartell A, Ulmert D, Härkönen P, Wingren AG: Low expression of SHP-2 is associated with less favorable prostate cancer outcomes. Tumor Biol 2013, 34(2):637-642.

18. Pinto A, Merino M, Zamora P, Redondo A, Castelo B, Espinosa E: Targeting the endothelin axis in prostate carcinoma. Tumor Biol 2012, 33(2):421-426.

19. Baetke SC, Adriaens ME, Seigneuric R, Evelo CT, Eijssen LM: Molecular pathways involved in prostate carcinogenesis: insights from public microarray datasets. PLoS One 2012, 7(11):e49831.

20. Carroll PR: Early stage prostate cancer-do we have a problem with over-detection, overtreatment or both? J Urol 2005, 173(4):1061-1062.

21. Ribeiro R, Monteiro C, Cunha V, Oliveira MJ, Freitas M, Fraga A, Príncipe P, Lobato C, Lobo F, Morais A, Silva V, Sanches-Magalhães J, Oliveira J, Pina F, Mota-Pinto A, Lopes C, Medeiros R: Human periprostatic adipose tissue promotes prostate cancer aggressiveness in vitro. J Exp Clin Cancer Res 2012, 31:32.

22. Filella $X$, Foj L, Milà $M$, Augé JM, Molina R, Jiménez W: PCA3 in the detection and management of early prostate cancer. Tumor Biol 2013, 34(3):1337-1347.

23. Delgado PO, Alves BC, Gehrke Fde S, Kuniyoshi RK, Wroclavski ML, Del Giglio A, Fonseca FL: Characterization of cell-free circulating DNA in plasma in patients with prostate cancer. Tumor Biol 2013, 34(2):983-986.

24. Diamandis EP: Prostate cancer screening with prostate-specific antigen testing: more answers or more confusion? Clin Chem 2010, 56(3):345-351.

25. Shariat SF, Karakiewicz PI, Suardi N, Kattan MW: Comparison of nomograms with other methods for predicting outcomes in prostate cancer: a critical analysis of the literature. Clin Cancer Res 2008, 14(14):4400-4407.

doi:10.1186/1756-9966-32-56

Cite this article as: Zhang et al:: Clinical significance of NUCB2 mRNA expression in prostate cancer. Journal of Experimental \& Clinical Cancer Research 2013 32:56.

\section{Submit your next manuscript to BioMed Central and take full advantage of:}

- Convenient online submission

- Thorough peer review

- No space constraints or color figure charges

- Immediate publication on acceptance

- Inclusion in PubMed, CAS, Scopus and Google Scholar

- Research which is freely available for redistribution 